\title{
Integration of Therapy in Reducing the Onset of Depression in Older Adults: Case Report
}

\author{
Anung Ahadi Pradana1, Junaiti Sahar ${ }^{2}$, and Henny Permatasari ${ }^{2}$ \\ ${ }^{1}$ Nursing Department STIKes Mitra Keluarga, Bekasi, West Java, Indonesia \\ ${ }^{2}$ Faculty of Nursing Universitas Indonesia, Depok, West Java, Indonesia \\ ORCID: \\ Anung Ahadi Pradana: https://orcid.org/0000-0001-6853-973X
}

\section{Abstract}

Depression in older adults is known to have a high impact on their quality of life. Depressive conditions experienced by older adults require the implementation of therapies that can reduce depression levels. The purpose of this report is to provide an evidence-based practice of integrated therapies programs to reduce depression levels in nursing care involving 10 elderly people. The integration program consists of cognitive restructuring therapy, deep breathing relaxation and Benson relaxation

Corresponding Author: Anung Ahadi Pradana ahadianung@gmail.com

Published: 15 March 2021

Publishing services provided by Knowledge E

(c) Anung Ahadi Pradana et al. This article is distributed under the terms of the Commons Attribution License, which permits unrestricted use and redistribution provided that the original author and source are credited.

Selection and Peer-review unde the responsibility of the IVCN Conference Committee.

\section{G OPEN ACCESS} interventions, guided autogenic, and behavior modification with laughter therapy. The implementation was carried out for 8 months, consisting of 2 sessions with each implementation for 4 months. The measurement results using the Geriatric Depression Scale (GDS)-15 showed a change in the depression level of older adults between preand post-treatment by 2.4 points. The results of this study are expected to be applied in community health services.

Keywords: Case study, Depression, Older adults, Therapy.

\section{Introduction}

Depression in the elderly is known to be one of the contributing factors that can be at high risk for the quality of life of the elderly in the community. Depression is a mental disorder characterized by various signs which include flat affect, loss of interest, decreased enthusiasm, low self-esteem, sleep disturbances, eating disorders to concentration problems where these symptoms must appear within 2 weeks (1).

WHO (2012) states that in 17 countries, 1 in 20 people has experienced a depressive episode in the past 1 year (2). Nearly $14 \%$ of the elderly in the world are estimated to have clinical symptoms relevant to depressive conditions (3). The results of Indonesia's Basic Health Research (2018) for people aged> 15 years showed that 706,689 (6.1\%) of people experienced depression. Based on age characteristics, as many as $6.5 \%$ of the 
population aged $55-64$ years, $8 \%$ of the population aged $65-74$ years, and $8.9 \%$ of the population aged $>75$ years experienced depression in Indonesia (4). This data shows that with increasing old age, the risk of depression will increase.

Depression is a problem that often occurs in the elderly population. Even though depression is not part of the natural aging process but as a negative consequence of changes in aging and risk factors that are exposed to the elderly. Important changes that occur in life as older adults aged can cause conditions of deep discomfort, stress, and sadness such as the death of a spouse, the departure of children from home, and loss of income due to retirement. Conditions of sadness and stress that last a long time that can trigger depression are active problems that most often arise in the (5).

Depressive conditions experienced by the elderly need the attention of health workers through the implementation of therapy that can reduce depression level. Several combinations of therapeutic interventions such as cognitive therapy, behavioral therapy, and relaxation therapy have been shown to have positive implications for elderly people with depression so that they can independently manage the level of stress they experience and reduce the risk of increasing the incidence of depression experienced (6-8). Combination therapy for depression is known to have higher effectiveness in reducing depression status than single therapy. In this case, the combined therapy includes cognitive therapy, relaxation therapy, and respiratory therapy (9).

Cognitive therapy is known to aim to change negative or maladaptive thoughts and behaviors of patients to become more positive or adaptive. One of the cognitive therapies that have a significant effect on depressive conditions is cognitive restructuring, this therapy has been shown to have a significant effect on changes in the mindset and behavior of depressed patients compared to several other therapies (such as physical activity) (10). While relaxation therapy has the goal of reducing excessive responses related to fight or flight response and returning individuals to a relaxed state (9).

In strengthening the relaxation process in the elderly who are depressed, it is necessary to have a process of changing behavior to be more adaptive to the stressor conditions that arise. In this case, simple behavior therapy is needed. Laughter therapy is a behavioral therapy that uses the positive effects of the release of endorphins and serotonin when individual laughs to reduce levels of anxiety, stress, depression, pain and boost the individual's immune system. The advantages of this therapy are that it is cheap, does not require certain situations or conditions, and does not require complicated assistive devices (11). Another study states that laughter therapy is an effective intervention to reduce negative mood conditions, stress, and pain in clients by being given once a day for 20-30 minutes and carried out for 5 days (12). 
Community nurses have an important role in the development of awareness and health of individuals and communities in dealing with clients with depression, including depression experienced by the elderly. A holistic implementation basically combines the body, mind, and spirit of the client to achieve the highest well-being. Healthy conditions without depression can be achieved if various factors that affect the elderly can support the implementation. This case study aims to identify the effectiveness of integrated cognitive therapy, relaxation therapy, and behavioral therapy through the implementation of cognitive restructuring therapy, deep breath relaxation, Benson relaxation, autogenic and laughter therapy in depressed elderly people.

\section{Methods and Equipment}

\subsection{Methods}

The application of Evidence-Based Nursing (EBN) was carried out in Kelurahan Mekarjaya, Depok, Indonesia for the period of October 2019-May 2020 with 10 elderly subjects randomly selected and experiencing depression as evidenced by an assessment using the Geriatric Depression Scale (GDS)-15 tool. The following inclusion criteria: (1) Clients aged $>60$ years, (2) The results of the GDS-15 assessment are more than 5/ have experienced depression, (3) The client does not experience cognitive impairment/ cognitive decline, (4) The client is able to communicate and obey orders well. Meanwhile, the exclusion criteria included: (1) Already experiencing cognitive decline, (2) Not residents of Kelurahan Mekarjaya.

The selection of the elderly is based on the inclusion and exclusion criteria. The elderly who are willing are then given an explanation of the purpose of implementing the programs. Before the start of the programs, the elderly and families were given information about depression. And after that, they were screened for depression using GDS-15 in the period before and after the intervention for 4 months. The implementation is divided into 2 sessions, each of which consists of 5 elderly people, with the aim of facilitating monitoring of the implementation of the given implementation.

Implementation is done through training and mentoring in the initial 5 sessions consisting of session 1 for cognitive restructuring, session 2 for deep breath relaxation techniques, session 3 for Benson relaxation, session 4 for autogenic, and session 5 for laughter therapy everyday for 4 months. After the client able to do it independently (autogenic needs assistance), then monitoring is carried out every week for 4 months 
and finally measuring the depression status using the GDS-15 again to assess the success of the program.

\section{Results}

The program implementation is carried out in 2 sessions, where session one starts in October 2019-January 2020 with direct monitoring of clients, and session two starts in February-May 2020 with direct monitoring and through the WhatsApp feature due to the condition of COVID-19.

The activity begins with 1 session at the beginning to provide information related to depression for the elderly and conduct pre-intervention screening using GDS-15. In this phase, the authors ask for the consent and willingness of the elderly to participate in activities that will be carried out together for the next 4 months. At the next 5 meetings, the elderly were given an information and demonstration of cognitive restructuring therapy, deep breathing relaxation, Benson relaxation, autogenic (with mentoring), and laughter therapy. After the elderly are able to carry out activities independently, monitoring and evaluation are carried out in 1 visit every week. After implementing the program for 4 months, it was found that there was a significant change in depression status in the elderly. The results can be seen in table 1.

TABLE 1: Problems and pre- and post-depression score in managed families

\begin{tabular}{|c|c|c|c|c|c|c|}
\hline \multirow[t]{2}{*}{ No. } & \multirow{2}{*}{$\begin{array}{l}\text { Managed } \\
\text { Families }\end{array}$} & \multirow{2}{*}{$\begin{array}{l}\text { Primary } \\
\text { Problem }\end{array}$} & \multirow[t]{2}{*}{ Other Problem } & \multicolumn{2}{|c|}{ Depression Score } & \multirow[t]{2}{*}{ Differences } \\
\hline & & & & Pre- & Post- & \\
\hline 1 & Mr. K (79 y.o) & Depression & Hypertension & 9 & 5 & -4 \\
\hline 2 & Mrs. K (65 y.o) & Depression & Hypertension & 10 & 6 & -4 \\
\hline 3 & Mr. N (63 y.o) & Depression & Hypertension & 7 & 6 & -1 \\
\hline 4 & Mr. A (70 y.o) & Depression & Hypertension & 8 & 7 & -1 \\
\hline 5 & Mr. N (75 y.o) & Depression & Hypertension & 9 & 7 & -2 \\
\hline 6 & Mrs. M (64 y.o) & Depression & Hypertension & 8 & 5 & -3 \\
\hline 7 & Mrs. K (70 y.o) & Depression & Hypertension & 9 & 6 & -3 \\
\hline 8 & Mrs. T (60 y.o) & Depression & Gout Arthritis & 9 & 7 & -2 \\
\hline 9 & Mrs. I (66 y.o) & Depression & $\begin{array}{l}\text { Rheumatoid } \\
\text { Arthritis }\end{array}$ & 8 & 5 & -3 \\
\hline \multirow[t]{2}{*}{10} & Mrs. N (63 y.o) & Depression & Hypertension & 8 & 7 & -1 \\
\hline & \multicolumn{3}{|c|}{ Average } & 8.5 & 6.1 & 2.4 \\
\hline
\end{tabular}

The results obtained during the process showed a change in depression level (measurement using the geriatric depression scale (GDS)-15) experienced by the elderly. The results above indicate that before nursing intervention, the mean depression status of 
the elderly was 8.5 , while the mean after the intervention was 6.1, which means that there was a change in the mean of 2.4, the largest decrease that occurred was 4 points experienced by Mrs. K.

\section{Discussion}

The application of integrated therapy for the reduction of depression level in the elderly showed significant results with a mean reduction of 2.4 points on the GDS-15 format scale. The use of combined therapy carried out by nurses is supported by several research sources which state that a combination of several therapies can provide more positive benefits for the elderly. Research conducted in Thailand shows that combining intervention programs consisting of a series of activities consisting of positive imaginary therapy, relaxation techniques, mind restructuring, acceptance of past trauma, and strengthening of interpersonal relationships can have positive implications in reducing depression in the elderly (6).

The integration of interventions for depressed elderly people is not a new thing. Research states that mild depression sufferers should be treated with nonpharmacological interventions to avoid the risk of unnecessary treatment, nonpharmacological interventions for the treatment of depression in the long term should be designed to meet physical challenges, and psychology faced by the elderly who experience depression (13). Research conducted [14] shows that a combined therapeutic approach consisting of physical activity, a healthy diet, social activity, and cognitive restructuring for 12 weeks can reduce the level of depression experienced by elderly people with major depressive disorders.

The provision of integrated therapy for the elderly is aimed at those at the level already showing symptoms, from mild to moderate depression. This is in accordance with research conducted [15] which states that elderly people who experience mild depression and tend not to be life-threatening can be given non-medical intervention. The provision of integrated therapy is also in accordance with the therapeutic suggestions described in Phase 1 interventions consisting of increased physical activity, increased nutrition, social interaction, provision of education, and counseling are needed for elderly people who experience mild depression or who are already showing depressive symptoms and decreased motivation. Providing written information as well as family and caregiver involvement can significantly affect the implementation of phase 1 intervention. In phase 2 interventions aimed at patients with mild-moderate depression, the provision of cognitive-behavioral interventions at low intensity can be additional to 
be given along with the therapy given in phase 1. Psycho-therapy medication can also be done if it is relevant and really needed because its addictive nature can make the elderly experience dependence. While phase 3 and phase 4 require higher medical therapy because the level of depression experienced by the elderly has entered the severe and life-threatening category.

National Institute for Health and Care Excellence (NICE) United Kingdom (2009) provides a list of interventions that can be provided for people with mild to severe depression, the combined form of intervention consists of 4 phases where the intervention in phase 1 (suspected mild depression) consists of assessment, Support therapy, psycho-education, active monitoring and referral to health services. Phase 2 (mildmoderate depression) consists of low-intensity psycho-social interventions, psychological interventions, provision of medication and referral to health services. Phase 3 (moderate-severe depression) consists of on intervention providing medication, highintensity psychological intervention, giving combination therapy, and collaborative care. And phase 4 (major depression with the risk of endangering life) consists of intervention giving medication, high-intensity psychological intervention, giving ECT, crisis management, giving combination therapy, and if necessary hospitalization.

Another factor that increases the severity and becomes the reason for the need to implement integrated therapy is the perception of poor health experienced by the elderly. Research conducted by [17] states that the perception of poor health in the elderly makes them more likely to experience depression, they are 10 times more prone to depression when compared to elderly people who have a perception of good health. Poor health perceptions in the elderly directly indicate the negative functional consequences experienced by the elderly.

Integrated therapies was formed as an answer to the problem of depression in the elderly which is still often considered not too important to be resolved, whereas elderly people who experience depression have a tendency to experience a decrease in the quality of life both bio-psycho-social-spiritual. Depression risk factors that can affect the elderly include social-economic factors, satisfaction with health services, poor family relationships, and perceptions of poor health. Elderly people who experience depression have a higher risk of experiencing vulnerability than elderly people who are not depressed. Therefore health workers should pay more attention to this problem (18).

The high effectiveness of combining non-pharmacological interventions for depressed elderly people can also be seen in a study conducted [19] which developed IMP therapy to improve cognitive function in elderly people with depression. IMP therapy consists of a combination of several theories such as physical activity therapy, 
meditation, laughter therapy, and personal awareness that is done once a week for each session for 8 weeks, the result is an increase in cognitive function in elderly people who experience depression.

\section{Conclusions}

The integration of therapy for depression in the elderly can reduce the depression status experienced by an average decrease of 2.4 points. The role of health workers in a sustainable monitoring the elderly in implementing the program is one of the success factors of the program being implemented. The series of integrated therapies used in this program, such as cognitive restructuring, deep breathing relaxation, Benson relaxation, Autogenic, and laughter therapy has effectiveness in reducing depression status so that they can become a model in developing program implementation, especially in reducing depression in the elderly.

\section{Funding}

This work was supported by STIKes Mitra Keluarga publications program.

\section{Acknowledgement}

The authors would like to thank their colleague for their contribution and support to the research. They are also thankful to all the reviewers who gave their valuable inputs to the manuscript and helped in completing the paper.

\section{Conflict of Interest}

The authors have no conflict of interest to declare.

\section{References}

[1] National Institute of Mental Health. (2018). Depression. Retrieved September 15, 2019 from https://www.nimh.nih.gov/health/topics/depression/index.shtml.

[2] World Health Organization. (2012). Depression. Retrieved September 12, 2019 from www.euro.who.int/en/health-topics/noncommunicable-diseases/pages/news/ news/2012/10/depression-in-europe/depresion-definition. 
[3] Silva, V., et al. (2017). Quality of Life, Integrative Community Therapy, Family Support, and Satisfaction with Health Services Among Elderly Adults with and without Symptoms of Depression. Psychiatric Quarterly, vol. 88, pp. 359-69.

[4] Kementrian Kesehatan Republik Indonesia. (2018). Laporan Nasional Riset Kesehatan Dasar 2018 (1 ${ }^{\text {st }}$ ed.). Jakarta: Kemenkes RI, p. 581.

[5] Singh, C. and Sangwan, S. (2019). Depression among Senior Citizens Living with and without Family. Indian Journal of Health and Well -Being, vol. 10, issue 1-3, pp. 65-8.

[6] John, M. M. and Tungol, J. (2017). Humour Based Intervention Program (HBIP): A Pilot Study. Indian Journal of Positive Psychology, vol. 8, issue 4, pp. 611-5.

[7] Imai, Y., et al. (2018). Impact of Social Relationships on Income - Laughter Relationships among Older People: The JAGES Cross- Sectional Study. BMJ Open, vol. 8, Issue 4, pp. 1-11.

[8] Hayes-Skelton, S. A., Roemer, L. and Orsillo, S. M. (2013). A Randomized Clinical Trial Comparing an Acceptance-Based Behavior Therapy to Applied Relaxation for Generalized Anxiety Disorder. Journal of Consulting and Clinical Psychology, vol. 81, issue 5 , pp. 761-73.

[9] Cheng, K. S., Croarkin, P. E. and Lee, P. F. (2019). Heart Rate Variability of Various Video-Aided Mindful Deep Breathing Durations and its Impact on Depression, Anxiety, and Stress Symptom Severity. Mindfulness (N Y), issue 10, pp. 2082-2094.

[10] Huang, T., et al. (2015). Physical Fitness Exercise versus Cognitive Behavior Therapy on Reducing the Depressive Symptoms among Community-Dwelling Elderly Adults: A Randomized Controlled Trial. International Journal of Nursing Studies, vol. 52, issue 10, pp. 1542-52, dx.doi.org/10.1016/j.ijnurstu.2015.05.013.

[11] Hwang, S., Jeong, H. and Hwang, J. (2019). Effect of Laughter Therapy on Healthy Life: A Meta-Analysis. Journal of the Korea Convergence Society, vol. 10, issue 9, pp. 291-9.

[12] Journ, S-J. and Lee, E-S. (2019). The Effects of Laughter Therapy on Moods, Pain, and Stress of Hospitalized Hospice Patients. Journal of the Korea Convergence Society, vol. 10, issue 11, pp. 481-9.

[13] Yoon, S., Moon, S. S. and Pitner, R. (2018). Effective Treatments of Late-Life Depression in Long-Term Care Facilities: A Systematic Review. Research on Social Work Practice, vol. 28, issue 2, pp. 116-30.

[14] Roh, H. W., et al. (2020). A 12-week Multidomain Intervention for Late-Life Depression: A Community- Based Randomized Controlled Trial. Journal of Affective Disorders, vol. 263, pp. 437-44, doi.org/10.1016/j.jad.2019.12.013.

[15] Vaid, N. (2015). Depression in the Elderly. InnovAiT, vol. 8, issue 9, pp. 555-61. 
[16] National Institute for Health and Care Excellence (NICE) United Kingdom. (2009). Depression in Adults: Recognition and Management. Retrieved from https://www. nice.org.uk/guidance/CG90.

[17] Silva, A. K. A. G., et al. (2019). Depressive Symptoms in Elderly People. Journal of Research: Fundamental Care Online, vol. 11, pp. 297-303.

[18] Chu, W., et al. (2019). The Relationship Between Depression and Frailty in Community- Dwelling Older People: A Systematic Review and Meta-Analysis of 84,351 Older Adults. Journal of Nursing Scholarship, vol 0, issue 0, pp. 1-13.

[19] Ahn, H. I. and Hyun, M. K. (2019). Integrative Medicine Research Effectiveness of Integrative Medicine Program for Dementia Prevention on Cognitive Function and Depression of Elderly in a Public Health Center. Integrative Medicine Research, vol. 8, issue 2, pp. 133-7, doi.org/10.1016/j.imr.2019.04.008. 